\title{
PENGARUH PENGGUNAAN KOIL RACING TERHADAP UNJUK KERJA PADA MOTOR BENSIN
}

\author{
Subroto \\ Jurusan Mesin Fakultas Teknik \\ Universitas Muhammadiyah Surakarta \\ JL. A. Yani Pabelan-Kartasura Tromol Pos 1 Telp. (0271) 715448 Surakarta.
}

\begin{abstract}
ABSTRAK
Untuk mendapatkan pembakaran yang optimal pada motor bensin dipengaruhi banyak hal antara lain:perbandingan udara-bahan bakar, homegen campuran, waktu penyalaan, besarnya tegangan koil, jarak elektrode busi dan lain-lain. Tujuan dari penelitian ini adalah untuk mengetahui perbandingan pengaruh penggunaan koil standart dengan koil racing terhadap unjuk kerja pada motor bensin. Pengujian unjuk kerja motor bensin dilakukan menggunakan dynamometer hidraulik, dengan cara membebenani gaya pengeremen pada putaran tertentu. Torsi dihitung berdasarkan gaya pengeremanyang terjadi dikalikan dengan panjang lengan pada dynamometer, selanjutnya torsi diketahui daya dapat dihitung. Pengukuran konsumsi bahan bakar dapat diketahui pada gelas ukur waktu pengujian berlangsung. Motor bensin dengan koil standart diuji unjuk kerjanya digunakan sebagai pembanding, kemudian dilanjutkan pengujian unjuk kerja dua koil racing. Penelitian menghasilkan kesimpulan penggunanan jenis koil berpengaruh terhadap unjuk kerja pada motor bensin. Penggunaan Koil Racing menghasilkan unjuk kerja yang lebih baik yaitu daya, dan torsi lebih besar dengan konsumsi bahan bakar yang lebih kecil.
\end{abstract}

Kata Kunci: motor bensin, koil, unjuk kerja

\section{PENDAHULUAN}

Sarana transportasi dalam kehidupan ini merupakan sarana yang tidak dapat dihindari pemakaiannya, terlihat dari kebutuhan transportasi sebagai penunjang perekonomian. Sarana transportasi ini semakin meningkat sejalan dengan meningkatnya taraf perekonomian masyarakat, hal ini dapat kita rasakan dengan pemerataan hasil-hasil pembangunan yang telah dilakukan oleh pemerintah. Dari berbagai macam sarana transportasi yang beroperasi maka jenis motor bakar toraklah yang banyak dioperasikan, dan pemakaian akan bahan bakar pun sangatlah dominan.

Di sisi lain seiring dengan meningkatnya sarana transportasi yang telah memberikan ber- macam-macam kemudahan serta kelebihan, akan memberikan dampak yang negatif atau kurang menguntungkan. Dampak-dampak tersebut diantaranya juga dapat diperhatikan pada segi penyediaan sumber daya alam (kandungan minyak bumi) maupun segi kesehatan lingkungan.

Dalam segi penyediaan sumber daya alam, sebagaimana kita ketahui bahwa minyak bumi sampai dengan saat ini masih merupakan sumber energi andalan utama di dunia, padahal minyak bumi tidak dapat diproduksi dalam pabrik. Dengan demikian persediaan minyak bumi dapat dikatakan terbatas, untuk itu harus diusahakan efisiensi dalam pemakaiannya.

Dengan semakin meningkatnya konsumsi bahan bakar, akan berdampak pada produksi 
gas sisa-sisa hasil pembakaran yang semakin besar pula. Ini berarti semakin meningkatnya polusi udara. Salah satu cara yang dapat dilakukan guna mengefisienkan pemakaian bahan bakar dalam menghemat pemakaian minyak bumi adalah dengan mengusahakan proses pembakaran di dalam ruang bakar sebaik mungkin. Alasan inilah yang juga dilakukan oleh para mekanik dalam proses menghasilkan daya yang maksimal pada mesin. Ada beberapa hal yang dapat dilakukan yaitu dengan cara memperbesar perbandingan kompresi yang akan meningkatkan angka kompresi dan tekanan pembakaran, pencampuran atau penggunaan bahan bakar yang tepat serta dengan cara merubah sistim pengapian dalam mesin motor tersebut. Dengan usaha memperhatikan dan menyempurnakan para-meter yang mempengaruhinya, salah satu di-antaranya adalah pengubahan sistem pengapian dalam hal ini penggantian Koil Standart Pabrikan dengan menggunakan Koil Khusus Performance Tinggi (Koil Racing) yanghal ini dilakukanuntuk memperbaiki proses pembakaran didalam ruang bakar.

Terdorong keingintahuan terhadap pengaruh penggantian Koil pada Mesin Sepeda Motor, maka dilakukan penelitian Pengaruh Penggunaan Koil Racing terhadap Unjuk Kerja pada mesin sepeda motor Honda Astrea Grand.

\section{Perumusan Masalah}

Dalam penelitian ini dirumuskan masalah yaitu: Apakah dengan penggantian Koil Racing akan berpengaruh terhadap unjuk kerja

\section{Batasan Masalah}

Pembatasan masalah dimaksudkan agar permasalahan yang dibahas tidak melebar, maka dalam penelitian ini hanya dibatasi pada penelitian pembandingan pengaruh penggunaan Koil Racing dengan Koil Standart Keluaran Pabrikan terhadap unjuk kerja mesin Honda Astrea Grand.

\section{Tujuan Penelitian}

Penelitian ini bertujuan untuk mengetahui perbandingan pengaruh penggunaan Koil Racing dengan Koil Standart terhadap Unjuk Kerja mesin Honda Astrea Grand.

\section{TINJAUAN PUSTAKA}

Boentarto (2002), dalam bukunya Perawatan dan Pemeliharaan Motor Bensin menjelaskan, Koil merupakan komponen pengapian yang menentukan baik tidaknya pembakaran sedangkan pembakaran menentukan boros tidaknya bensin. Koil pengapian dengan performance tinggi (Koil Racing) digunakan untuk menghasilkan tegangan percikan bunga api yang tinggi, koil ini mampu menyediakan penyimpanan energi besar yang dapat digunakan para mekanik dalam memodifikasi sebuah motor. Tegangan yang dihasilkan pada penggunaan koil ini jauh lebih besar yaitu mencapai 10.000 25.000 volt sehingga bunga api listrik yang terjadi pada busi jauh lebih besar dan kuat.

Setyawan (2000), dalam penelitiannya dengan judul Peningkatan Unjuk Kerja Mesin Bensin 4 Langkah dengan Penggunaan Busi Splitfire SF 392D Dan Kabel Busi Hurricane, bahwabusi sangat berpengaruh untuk menghasilkan busur api listrik terhadap kesempurnaan proses pembakaran yang terjadi di dalam ruang bakar. Hasil penelitiannya menunjukkan bahwa dengan menggunakan busi Splitfire SF 392 D dan kabel busi Hurricane, maka waktu pengapian harus disesuaikan untuk mendapatkan daya yang optimal. Peningkatan daya rata-rata yang dihasilkan dari pengujian adalah sebesar 3,8\%.

Prasetia (2005), dalam penelitiannya mengenai Pengaruh Jarak Kerenggangan Elektroda Busi Terhadap Efesiensi Pemakaian Bahan Bakar Pada Mesin Sepeda Motor Suzuki Shogun, bahwa busi sangat berpengaruh untuk menghasilkan bunga api listrik terhadap kesempurnaan proses pembakaran yang terjadi di dalam ruang bakar. Dari hasil penelitiannya menunjukkan bahwa besarnya jarak kerenggangan elektroda busi untuk mencapai efisiensi penggunaan bahan bakar pada keadaan putaran mesin rendah $4000 \mathrm{rpm}$ adalah $0,8 \mathrm{~mm}$ yaitu 253,9 g / hp h. Penggunaan bahan bakar pada putaran mesin $9000 \mathrm{rpm}$ yang paling boros dihasilkan pada jarak kerenggangan elektroda busi 1,3 mm yaitu sebesar 93,1 g / hp h. Untuk jarak kerenggangan elektroda busi $0,7 \mathrm{~mm}$ sampai dengan 0,8 mm sebagaimana yang 
ditentukan dalam buku pedoman pemakaian dan perawatan shogun adalah termasuk ukuran yang sesuai untuk dapat mencapai efisiensi pemakaian bahan bakar baik pada kondisi putaran mesin rendah (4000 rpm) maupun putaran mesin tinggi (9000 rpm).

\section{Dasar Teori}

Sistim ignition umumnya terdiri dari : switch ignition, coil ignition, magneto dan busi. Sistim ignition yang dipakai pada sepeda motor secara umum dapat diklasifikasikan oleh tiga tipe berikut ini:

1. Sistim ignition magneto

Magnit yang dipakai pada sepeda motor digunakan sebagai penghasil tegangan listrik biasanya juga berfungsi sebagai roda daya. Dimana magnit ditempatkan pada poros engkol (crankshaft).

2. Sistim ignition Baterai (Accu)

Dengan penggunaan baterai akan memudahkan mesin untuk distart kerena tegangan yang dihasilkan oleh baterai lebih stabil sehingga sistim pengapian tidak mudah rusak.

3. Sistim CDI (Capasitor Discharge Ignition) Sistim CDI merupakan penyempurnaan dari sistim kontak pada platina yang mudah teroksidasi atau kotor dan mengakibatkan mesin susah distart. Dengan tujuan menghilangkan kesukaran pada titik-titik kontak, maka dikembangkanlah sistim CDI.

\section{Koil}

Koil merupakan salah satu bagian terpenting dalam pengapian pada motor Spark Ignition Engines, karena Koil merupakan komponen pengapian yang menentukan baik tidaknya proses pembakaran dalam ruang bakar sedangkan baik tidaknya pembakaran akan menentukan boros tidaknya bensin. Koil difungsikan sebagai pengubah arus tegangan rendah menjadi tegangan tinggi untuk menghasilkan pijaran bunga api listrik pada busi dan dilihat dari fungsinya koil merupakan sumber nyata dari tegangan yang dibutuhkan dalam proses pembakaran. Koil menghasilkan tegangan tinggi dengan prinsip induksi dimana tegangan listrik pada batery, tegangan batery adalah rendah (6-12Volt) dan dinaikan sampai 500025.000 Volt.

Sistim pengapian ini meliputi sumber arus (batery/accu atau generator), kunci kontak, CDI/ platina, Koil, kabel dan busi. Tegangan tinggi menimbulkan pengapian koil yang mempunyai dua belitan, belitan tegangan rendah dan tegangan tinggi. Kedua-duanya membeliti sekeliling suatu inti, jika titik kontak menutup, arus aliran melalui belitan tegangan rendah dan inti menjadi magnit. Lapangan magnit menurun dengan sangat cepat apabila titik kontak terbuka dan dengan lapangan magnit berubah induksi tegangan tinggi dalam belitan tegangan tinggi, tenaga magnetik berubah menjadi tenaga listrik sehingga tegangan dapat naik sampai sekitar 25.000 Volt.

Secara fisik koil dikonstruksi mirip dengan trafo yang dirancang untuk operasian saluran rendah, dari sudut fungsinya koil merupakan sumber yang nyata dari tegangan pembakaran. Pada bagian tengahnya koil berisi batangan logam yang dilapisi dengan inti besi, sekitar inti dan yang terisolasi dililit penyekat kumparan sekunder (tegangan tinggi) dengan jumlah lilitan kawat tembaga yang sangat tipis dan lebih banyak dari pada kumparan primer. Dibagian luar dari penyekat dan bagian yang terisolasi dililit penyekat kumparan primer dengan lilitan kawat tembaga yang lebih besar, perbandingan lilitan antara penyekat sekunder dan kumparan primer adalah 60 sampai dengan 150 .

Berdasarkan bentuk serta kegunaannya Koil dapat dibedakan menjadi beberapa bagian: 1. Desain Koil Standart

Koil pengapian ini digunakan untuk pengapian tegangan tinggi pada mesin sepeda motor, guna mengurangi gangguan dari luar konstruksi koil tersebut dibungkus dengan plastik yang dicairkan dan dilekatkan dengan konstruksi bentuk standart.

2. Desain Koil pengapian performance tinggi (Koil Racing)

Koil ini sedikit berbeda dengan koil standart dimana koil ini sengaja diciptakan untuk menghasilkan tegangan yang tinggi guna menyempurnakan proses pembakaran yang 
terjadi pada ruang bakar. Pada dasarnya Koil Racing merek KITACO K2R dikonstruksikan hampir sama dengan koil Standart Pabrikan, namun dalam penelitian ini tidak membahas mengenai perbedaan atau kesamaan yang ada pada koil.

Dalam beberapa hal koil pengapian performance tinggi tidak mampu mengurangi panas yang diakibatkan dari tagangan listrik keudara luar. Koil yang sedemikian itu tidak dapat dibuat dengan ukuran yang lebih besar untuk memberikan permukaan radiasi lebih. Meskipun demikian, sebagai jawaban atas masalah itu penghambat penyekat primer dikurangi lewat penggunaan kumparan tembaga yang lebih besar. Dengan demikian pembatasan koil puncak bentuk aliran total rangkaian resistor tidak mengalami perubahan, tahanan seri tersebut mengurangi beban panas pada koil pengapian karena aliran panas dibangkitkan pada resistor. Dengan cara itu energi pengapian yang tersedia memadai sebagai pengganti pengurangan energi baterai sewaktu-waktu. Proses itu dinamakan "dorongan start tegangan"

\section{Prestasi Mesin}

Prestasi mesin adalah kemampuan mesin ditinjau dari daya, torsi, dan SFC terhadap putaran mesin.

a. Pengukuran Torsi

Torsi adalah perkalian antara gaya dengan jarak yang dapat dirumuskan seperti :

$$
\begin{aligned}
\mathrm{T} & =\mathrm{F} . \mathrm{l} \\
& =\mathrm{m} . \mathrm{g} . \mathrm{l}
\end{aligned}
$$

dimana :

$$
\begin{aligned}
\mathrm{T}= & \text { Momen Torsi }(\mathrm{Nm}) \\
\mathrm{m}= & \text { Massa yang terukur dalam dyna- } \\
& \text { mometer }(\mathrm{kg}) \\
\mathrm{g}= & \text { Percepatan gravitasi }\left(\mathrm{m} / \mathrm{s}^{2}\right) \\
\mathrm{l}= & \text { Panjang lengan pada dynamometer }
\end{aligned}
$$
(m)

b. Daya

Daya adalah kerja yang dihasilkan sebuah mesin dalam suatu percobaan, yang dapat dirumuskan:

$$
\mathrm{P}=\frac{2 \pi \cdot n \cdot T}{60000}(\mathrm{~kW})
$$

dimana :

$\mathrm{P}=$ Daya mesin $(\mathrm{kW})$

$\mathrm{n}=$ Putaran mesin (rpm)

$\mathrm{T}=\operatorname{Torsi}(\mathrm{Nm})$

c. Konsumsi Bahan Bakar Spesifik (SFC)

Konsumsi bahan bakar spesifik adalah jumlah bahan bakar yang diperlukan untuk menghasilkan daya efektif sebesar satu kW selama satu jam, dapat dirumuskan:

$$
\begin{aligned}
\mathrm{SFC} & =\frac{m f}{P}(\mathrm{~kg} / \mathrm{kW} . \mathrm{hr}) \ldots \ldots . .(3) \\
\mathrm{mf} & =\frac{\mathrm{b}}{\mathrm{t}} \cdot \frac{3600}{1000} \mathrm{xn}_{\mathrm{bb}}(\mathrm{kg} / \mathrm{h}) \ldots(4)
\end{aligned}
$$

dimana:

$\mathrm{mf}=$ konsumsi bahan bakar $(\mathrm{kg} / \mathrm{h})$

$\mathrm{P}=$ daya $(\mathrm{kW})$

$\mathrm{b}=$ volume buret yang dipakai dalam pengujian (cc)

$\mathrm{t}$ = waktu yang diperlukan untuk mengosongkan buret (s)

$\tilde{\mathrm{n}}_{\mathrm{bb}}=$ massa jenis bahan bakar $(\mathrm{kg} / \mathrm{l})$

\section{METODE PENELITIAN}

Dalam penelitian ini desain yang digunakan termasuk desain eksperimen dengan melakukan beberapa perlakuan dan tindakan pengamatan terhadap suatu variabel, yang dilakukan secara sistematis. Dimana dalam desain ini suatu perlakuan yaitu penggunaan Koil Performance Tinggi (Koil Racing) dikenakan pada suatu obyek penelitian yaitu mesin sepeda motor HondaAstrea

\section{Alat-alat Penelitian}

1. Mesin Dinamometer

2. Tool Set

3. Alat ukur

- Hand Tachometer Digital, untuk mengatur putaran mesin.

- Buret, untuk mengukur volume bahan bakar.

- Stopwatch, untuk mengukur waktu dalam setiap perlakuan. 


\section{Diagram Alir Penelitian}

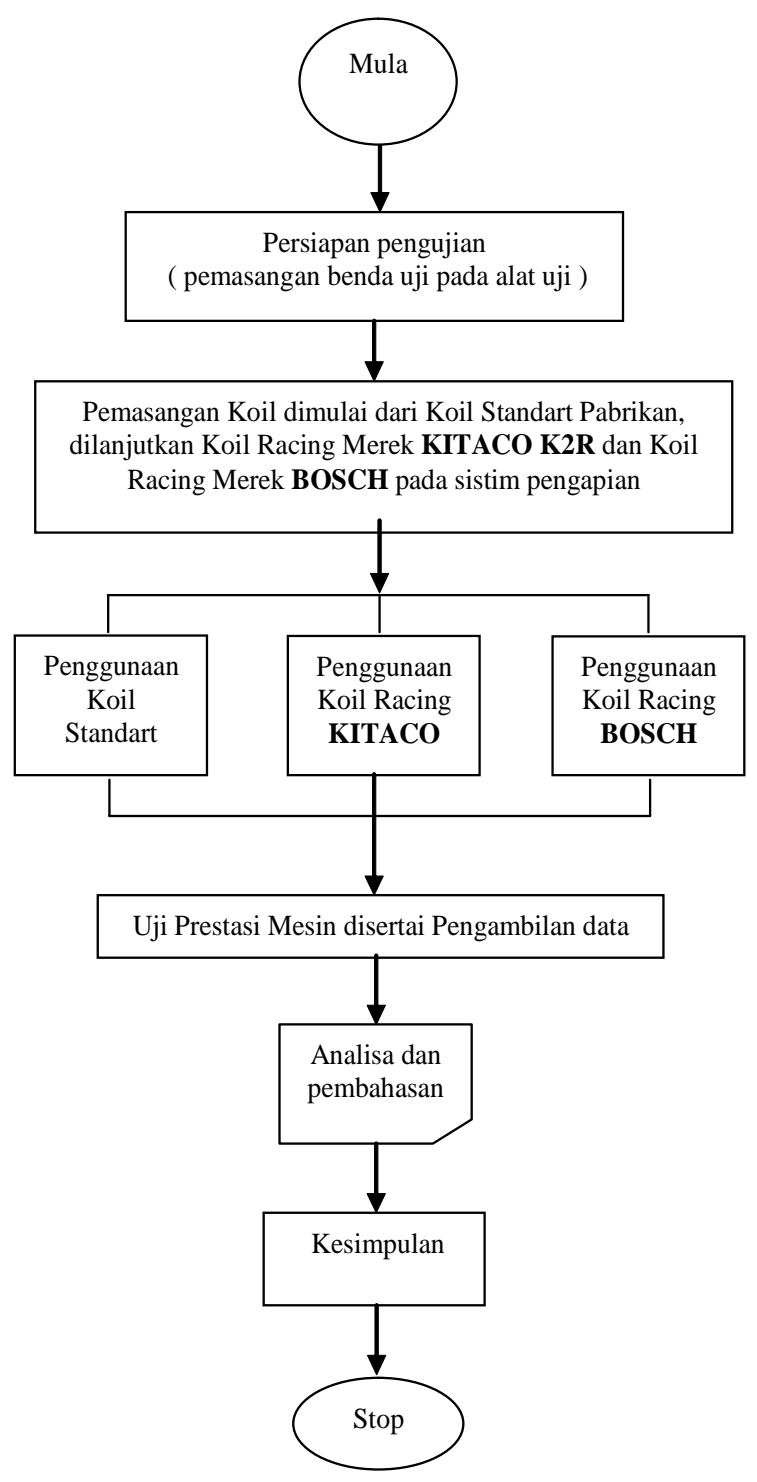

Gambar 1. Diagram Alir Penelitian

\section{Sampel/Spesimen Uji}

Dalam penelitian ini, sampel yang digunakan merupakan produk yang telah beredar dipasaran atau populasinya dapat kita temui dipasaran atau dalam kehidupan sehari-hari yaitu sebagai berikut:

1. Mesin yang digunakan adalah mesin sepeda motor Honda Astrea Grand

2. Koil yang digunakan ada tiga jenis yaitu Koil standart keluaran pabrikan, Koil Racingmerek KITACO K2R dan Koil Racing merek BOSCH.

\section{Lokasi Penelitian}

Penelitian yang dilaksanakan bertempat di Laboratorium Konversi Energi FT - UGM

\section{Jalannya Penelitian}

Sebelum mesin dioperasikan, perlu adanya pemeriksaan bahan bakar pada tangki bahan bakar, suplai air yang mengalir pada dynamometer. Melakukan pemasangan koil pada sistim pengapian dimulai dari koil standart pabrikan, koil Racing merek KITACO K2R dan merek BOSCH secara bergantian.

Setelah pemeriksaan selesai kemudian mesin dioperasikan untuk pemanasan awal pada putaran 1000-3000 rpm selama 2-3 menit. Kemudian naikkan putaran menjadi 4000 rpm setelah beberapa saat mulai melakukan pengambilan data, catat torsi yang dihasilkan pada dynamometer dan waktu konsumsi bahan bakar per 4 cc perlakuan ini diulang sebanyak tiga kali. Hal yang sama akan diperlakukan untuk putaran mesin 6000 dan $8000 \mathrm{rpm}$. Setelah pengambilan data selesai turunkan putaran mesin dan matikan, kemudian pada sistim pengapiannya diganti menggunakan Koil merek KITACO, tahapan dan perlakuan dalam pengambilan data sama dengan penelitian yang sebelumnya dan akan diulang kembali pada pengambilan data terhadap koil merek BOSCH.

\section{HASIL DAN PEMBAHASAN}

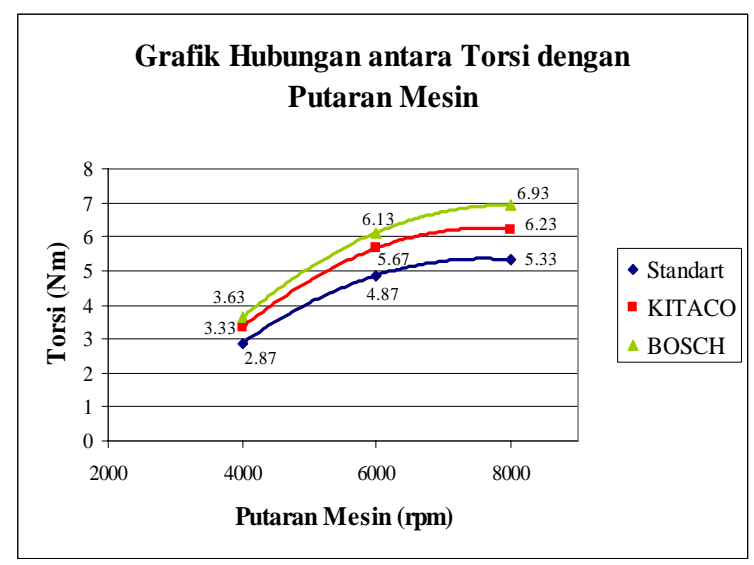

Gambar 2. Hubungan antara Torsi dengan Putaran Mesin 
hpjam, pada Koil KITACO mengkonsumsi sebesar 63,64 gr/hpjam, dan pada Koil standart mengkonsumsi bahan bakar sebesar 76,852 gr/ hpjam.

\section{KESIMPULAN}

Berdasarkan analisis dan perhitungan data hasil penelitian dapat diambil kesimpulan bahwa:

1. Pada penelitian diketahui penggunaan koil racing memperoleh hasil unjuk kerja mesin yang lebih baik dibanding koil standart pabrikan.

2. Penggunaan koil racing menghasilkan daya yang lebih baik/tinggi pada setiap putaran mesin dibanding koil standart, hal ini disebabkan proses pembakaran campuran bahan bakar dan udara yang terjadi dalam ruang bakar lebih baik atau lebih cepat, sehingga daya yang dihasilkan menjadi tinggi pula.

3. Koil Racing mengkonsumsi bahan bakar lebih sedikit (irit) dibandingkan Koil Standart Pabrikan akan tetapi merek BOSCH mengkonsumsi bahan bakar yang paling sedikit (irit) dibanding kedua koil yang lain.

4. Dalam penelitian diketahui bahwa Koil Racing BOSCH manghasilkan Unjuk Kerja Mesin yang terbaik, diikuti oleh Koil Racing KITACO K2R dan ketiga dihasilkan oleh Koil Standart Pabrikan.

\section{DAFTAR PUSTAKA}

Arend, BPM, Barenschot, H.,1980, Motor Bensin, Erlangga, Jakarta.

Arismunandar. W, Koichi, 1997, Motor Diesel Putaran Tinggi, Pradnya Paramita, Jakarta.

Arismunandar.w, 2002, Motor Penggerak Mula, ITB, Bandung. , 2005, Modifikasi Mesin atau Kimia, LIPI, Jakarta.

Buntarto, 2000, Perawatan Motor Bensin, Gama, Semarang.

Sitompul. D, 1991, Prinsip-Prinsip Konversi Energi, Erlangga, Jakarta.

Sunarta, Nakula, Furuhama, Shoichi, 1995, Motor Bakar Serbaguna, Pradya Paramita, Jakarta.

Supriatna. Y, 1998, Listrik pada Otomotif, Angkasa, Jakarta.

Sumarsono, 1999, Perawatan Kelistrikan pada Otomotif, Angkasa, Jakarta.

Setyawan (2000), Peningkatan Unjuk Kerja Mesin Bensin 4 Langkah dengan Penggunaan Busi Splitfire SF 392D Dan Kabel Busi Hurricane, Fakultas Teknik Univesitas Muhammadiyah Surakarta

Prasetia (2005), Pengaruh Jarak Kerenggangan Elektroda Busi Terhadap Efesiensi Pemakaian Bahan Bakar Pada Mesin Sepeda Motor Suzuki Shoguna, Fakultas Teknik Univesitas Muhammadiyah Surakarta

Willard. w, Pulkabrek, 1997, Enginering Fundamental Of The International Combustion Engine, Second Edition, Prantice Hall, New jersey. 